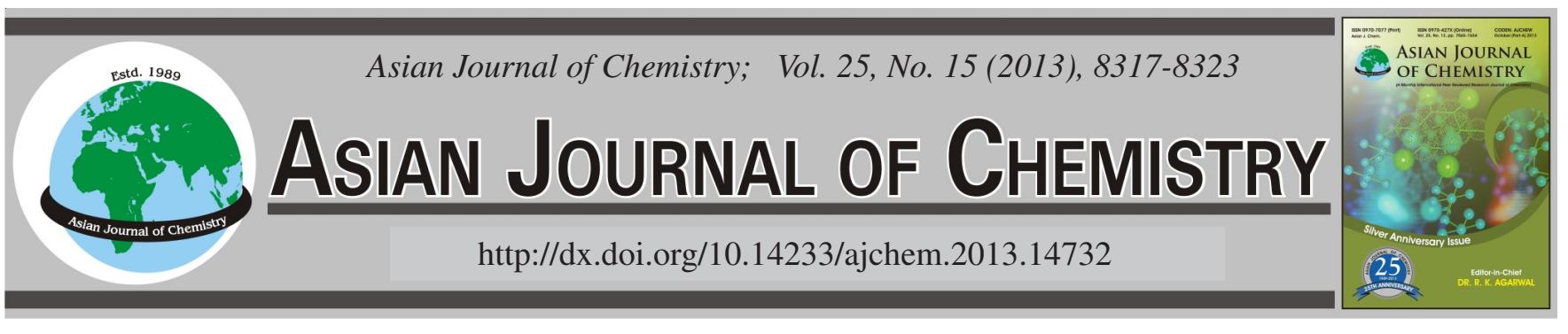

\title{
Formation of Methylolureas Under Alkaline Condition: A Theoretical Study
}

\author{
TaO Hong LI ${ }^{1,2}$ XIAO Guang XIE ${ }^{3}$ and Guan Ben Du ${ }^{1, *}$
}

${ }^{1}$ College of Wood Science and Technology, Nanjing Forestry University, Nanjing 210037, P.R. China

${ }^{2}$ Southwest Forestry University, Kunming 650224, P.R. China

${ }^{3}$ Department of Chemistry, Yunnan University, Kunming 650091, P.R. China

*Corresponding author: Tel: +86 871 3863472; E-mail: dgb689@ @wfu.edu.cn

\begin{abstract}
The base-catalytic reactions between urea and formaldehyde were investigated by using theoretical methods of B3LYP and MP2 with solvent effects included. The urea anion $\mathrm{H}_{2} \mathrm{NCONH}^{-}$produced by the reaction of urea with $\mathrm{OH}^{-}$can react with two forms of formaldehyde, $\mathrm{CH}_{2} \mathrm{O}$ and $\mathrm{CH}_{2}(\mathrm{OH})_{2}$, via nucleophilic addition and $\mathrm{S}_{\mathrm{N}}{ }^{2}$ mechanisms, respectively. The addition mechanism is energetically more favourable. The calculated potential energy barriers for the formations of mono-methylolureas (MMU), di-methylolureas (DMU) and tri-methylolureas (TMU) are close, suggesting that the $-\mathrm{NH}_{2}$ and $-\mathrm{HN}$ - groups have close reactivity toward formaldehyde or substitutions of methylol groups on urea do not significantly decrease the reactivity of the left reactive positions. Statistical factor may explain the observed lower reactivity of methylolureas than free urea. The steric hindrance is the main factor that rationalizes the absence of tetra-methylolurea in experiment.
\end{abstract}

Key Words: Base-catalytic, Urea, Formaldehyde, Methylolurea, Theoretical.

\section{INTRODUCTION}

Urea-formaldehyde adhesive resins are polymers that can be produced through the reactions between urea and formaldehyde. Because of the good performance and the low cost, the urea-formaldehyde resins are the most wildly used resins in modern wood industry. Although urea-formaldehyde resin has a history of over one and half century since its first introduction, studies in this field have never stopped because of the complexity of urea-formaldehyde chemistry ${ }^{1}$. Due to the low resistance of urea-formaldehyde resins against hydrolysis, emission of free formaldehyde during storage and use becomes their fatal shortcoming. To solve this problem, chemists in this filed tried many strategies to improve the synthetic methods ${ }^{2,3}$. For example, adding melamine to the U-F reaction system to produce so-called methylol urea-formaldehyde co-condensation resins is a good way to balance the formaldehyde emission and the properties of urea-formaldehyde resins $^{4-11}$. Structure analysis suggests that the changes of reaction conditions such as $\mathrm{pH}$, urea/formaldehyde molar ratio, reaction time and temperature result in much different structures and properties of urea-formaldehyde resins ${ }^{1,12}$. It has been the dream of the chemists in this field to obtain the resins which bear the expected structures. To reach the goal, many studies have to be carried out to investigate the details of a broad variety of possible reactions involved in the urea-formaldehyde resin synthesis.

The basic theory ${ }^{13-15}$ established in 1950 s pointed out that the formation of urea-formaldehyde resin includes two stages: the addition between urea and formaldehyde to form methylolureas (methylolation) and the following condensation. The methylolation generally occur under the alkaline condition (or acid condition) while the condensation is catalyzed by acid. To understand the reaction mechanisms and how the reactions depend on the conditions, some kinetics studies have been carried out ${ }^{14-16}$. However, limited details were disclosed because it is very hard to control the reactions with the presence of catalysis and many possible reactions occur at the same time. On the other hand, the reaction intermediates and products can not be separated. Therefore, the experimental results represent the overall reactions while the information about the competitive reactions that lead to different products can not be obtained. Because of the above reasons, literatures that focus on the mechanisms of urea-formaldehyde resin synthetic reactions are rare and the progress made on the relevant theories is slow.

Computational methods based on reliable quantum theories provide alternative choices and allow us to investigate each single reaction taking place in the process of ureaformaldehyde resin formation. Recently, we investigated the 
mechanisms and potential energy surfaces (PESs) of the acidcatalytic methylolation reactions of formaldehyde with urea and phenol ${ }^{17,18}$, the formation of methylene $\left(-\mathrm{CH}_{2}-\right)$ and methylene ether $\left(-\mathrm{CH}_{2}-\mathrm{O}-\mathrm{CH}_{2}-\right)$ linkages ${ }^{18}$. In the present work, we focus on the methylolation reactions between urea and formaldehyde under alkaline condition, attempting to provide some details that can not be observed by experiments and add some knowledge to the old topic. Considering the difficulties for the current theoretical solvent model to simulate the real solvent situation, the calculated results would be qualitative.

\section{COMPUTATIONAL METHOD}

The geometries of the reactants, intermediates, transition states (TS) and products were fully optimized at B3LYP/6$31+\mathrm{G}^{* 19-21}$ level of theory. For some reactions which involve weak interactions, the stationary points were re-optimized at MP2/6-31+G ${ }^{* * 22}$ level. To include the solvent effect, the PCM (polarizable continuum model) solvent model ${ }^{23,24}$ was used by defining water as the solvent. Considering that the hydrogen bonds formed between water molecules with urea, urea anion or $\mathrm{OH}^{-}$anion may affect the potential energy barriers of some proton-transfer reactions, explicit water molecules were added to simulate the specific salvation effects. After geometry optimization tests, it was found that at least three water molecules are necessary for stabilizing the complexes or transition states. Harmonic vibrational frequency calculations were performed at the same theoretical level to characterize the nature of each stationary point as a local minimum or a transition state. Zeropoint energy (ZPE) have been included to correct the relative energies. Intrinsic reaction coordination (IRC) calculations were also carried out to confirm the connectivities between minima and transition states. With solvent effect included, higher-level single point calculations were performed at MP2/ $6-311+\mathrm{G}^{* * 25,26}$ level with B3LYP/6-31+G ${ }^{*}$ optimized geometries. All the calculations were carried out with GAUSSIAN03 program package ${ }^{27}$.

\section{RESULTS AND DISCUSSION}

Formation of monomethylolurea (MMU): Our previous study ${ }^{18}$ suggested that the addition of urea to formaldehyde under neutral condition occurs in a concerted mechanism via a four-centered transition state (TS) with a potential energy barrier of $145.7 \mathrm{~kJ} / \mathrm{mol}$ at MP2/6-311+G $\mathrm{G}^{* *}$ level. No reactions were found for urea and methanediol which is the dominant form of formaldehyde in water solution. The acid acting as catalysis makes the formaldehyde (both the methanal and methanediol) protonated and the nucleophilic attack of urea becomes favourable. Under alkaline condition, the base $\left(\mathrm{OH}^{-}\right)$ plays a different role as catalysis. Francis et al. ${ }^{16}$ proposed that the $\mathrm{OH}^{-}$would abstract a proton from urea, producing an urea anion $\mathrm{NH}_{2} \mathrm{CONH}^{-}$which is a stronger nucleophile than neutral urea. It is a reasonable mechanism since urea is a weak acid toward strong base. Based on this catalytic mechanism, the possible reactions can be figured out as shown in Scheme-I.

Considering the DFT theoretical level B3LYP/6-31+G* may not good enough to describe the weak interactions, for the reactions (1-4) which involve hydrogen atom transfer and hydrogen bonds, the geometries of the stationary points were re-optimized using ab initio method MP2 with the basis set 6-31+G** . However, it can be seen in Fig. 1 that the results obtained at this level do not differ significantly from those of B3LYP/6-31+G* .

To verify whether the reaction (1) has a potential energy barrier, we performed calculations on it. The optimized geometries and the potential energy profile are shown in Fig. 1. It was expected that a hydrogen-bonding complex can be formed between urea and $\mathrm{OH}^{-}$anion, however collapsed structure was always encountered during geometry optimizations. This suggests that simple polarizable continuum model is not enough to describe the existence of such complex in solution and explicit water molecules which can form hydrogen bonds with the reactants must be added to represent the specific

$$
\mathrm{H}_{2} \mathrm{~N}-\stackrel{\mathrm{O}}{\mathrm{C}}-\mathrm{NH}_{2}+\mathrm{OH}^{-} \frac{k_{1}}{k_{-1}} \mathrm{H}_{2} \mathrm{~N}-\stackrel{\stackrel{\mathrm{O}}{\mathrm{C}}}{\stackrel{\mathrm{U}^{-}}{(}-\mathrm{NH}^{-}}+\mathrm{H}_{2} \mathrm{O}
$$

$\mathrm{CH}_{2}(\mathrm{OH})_{2} \frac{k_{2}}{k_{-2}} \mathrm{H}-\underset{\mathrm{F}}{\stackrel{\mathrm{O}}{\mathrm{C}}}-\mathrm{H}+\mathrm{H}_{2} \mathrm{O}$<smiles>CC(C)C=CC=O</smiles>

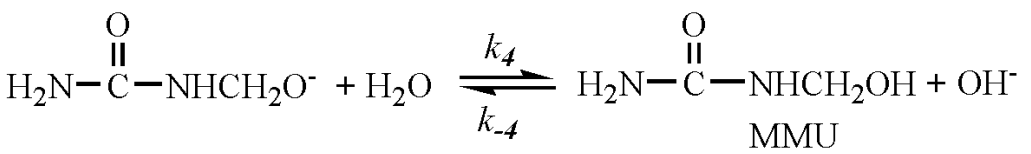

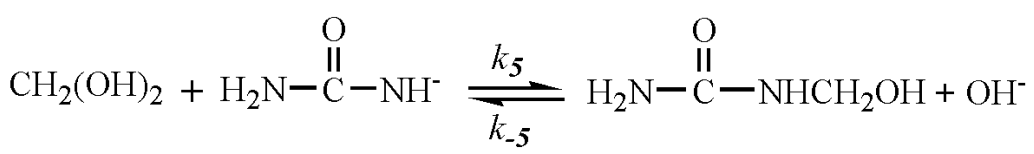

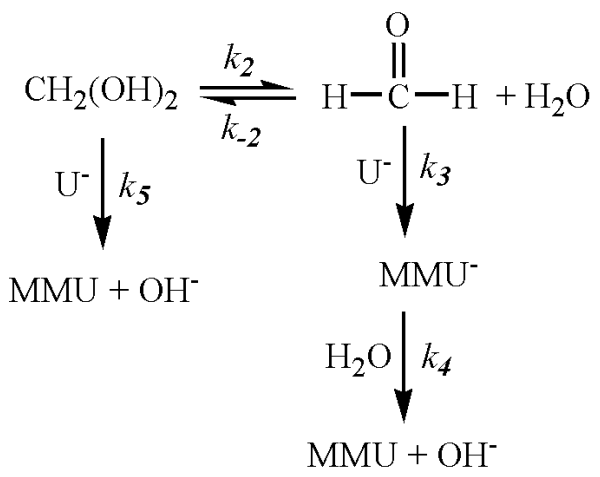

Scheme-I: Reactions proposed to be related with the formation of MMU 


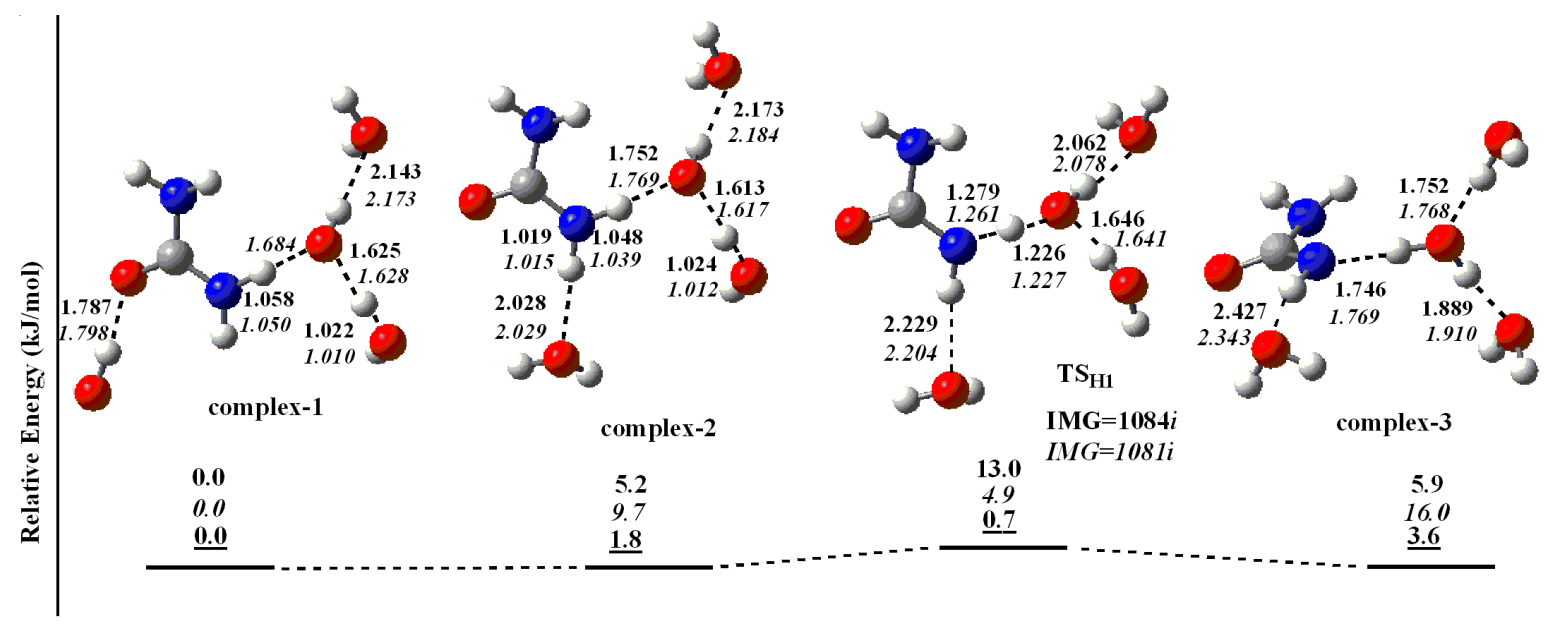

Fig. 1. Optimized geometries (bond lengths in $\AA$ ) for reaction (1) in Scheme-I at B3LYP/6-31+G* and MP2/6-31+G** (italic) levels, respectively, and the calculated relative energies at B3LYP/6-31+G*, MP2/6-31+G** (italic) and MP2/6-311+G** (underlined) levels, respectively

salvation effects. By adding one or two explicit water molecules, the optimizations also gave collapsed structures. When three water molecules were added, stable complexes as shown in Fig. 1 were located. Surely, if more water molecules were added, the model would be closer to the real situation. But with more weak interactions involved, the calculations become more difficult, especially for locating a transition state. Therefore, in the present study, further optimizations with more explicit water molecules were not performed.

In complex 1, the urea, $\mathrm{OH}^{-}$and three water molecules were bonded together by hydrogen bonds. In this structure, the lowest water forms hydrogen bond with the $\mathrm{C}=\mathrm{O}$ group. $\mathrm{A}$ strong hydrogen bond is formed between $-\mathrm{N}-\mathrm{H}$ and $\mathrm{O}-\mathrm{H}^{-}$, in consistent with the short bond length $1.684 \AA$ and the elongated $\mathrm{N}-\mathrm{H}$ bond $(1.058 \AA$ ). Based on this complex, a number of optimizations were carried out to locate a transition state that corresponding to the transfer of a hydrogen from atom $\mathrm{N}$ to O. However, a collapsed structure was always encountered. It was expected that a more stable complex in which the lowest water forms hydrogen bonds with both $\mathrm{C}=\mathrm{O}$ and $-\mathrm{NH}_{2}$ groups may exist, but such structure was also not located despite of numerous searches. Instead, a complex in which the lowest water forms a hydrogen bond with $-\mathrm{NH}_{2}$ was found, shown in Fig. 1 as complex $\mathbf{2}$ which is slightly less stable than complex 1. Starting from this complex, the target transition state was located. $\mathrm{TS}_{\mathrm{H} 1}$ represents the transfer of a hydrogen from $\mathrm{N}$ to $\mathrm{O}$ with an imaginary (IMG) frequency of 1084i, corresponding to the breakage of the $\mathrm{N}-\mathrm{H}$ bond and the formation of $\mathrm{H}-\mathrm{O}$ bond. Both B3LYP/6-31+G ${ }^{*}$ and MP2/6-31+G ${ }^{* *}$ suggest this process has a small barrier, while MP $2 / 6-311+\mathrm{G}^{* *}$ indicates it is barrierless. The complex $\mathbf{3}$ which was placed slightly above $\mathrm{TS}_{\mathrm{H} 1}$ by zero point energy-corrections can be viewed as a complex formed between urea anion with four water molecules. Obviously, the following collisions between urea anion and formaldehyde must overcome the barrier caused by the specific solvent effects. The calculated flat PES implying that a fast equilibrium between urea and urea anion can be established in alkaline solution. However, according to the weak acidic nature of urea, the formation of urea anion should be thermodynamically unfavourable and the concentration should be low.
Despite that the results of this study are qualitative, successfully modeling this reaction by adding three water molecules is a valuable experience which suggests simply employing the solvent model like polarizable continuum model is not enough to describe the hydrogen transfer reaction in water solution.

Reaction (2) in Scheme-I denotes the transformation between methanediol and methanal. This reaction is important because it determines which form of formaldehyde contributes more to the products. The identified mechanisms and potential energy profiles are shown in Fig. 2. Fig. 2(a) shows a mechanism where a hydrogen migrates from one hydroxide group to another, via the four-centered transition state $\mathrm{TS}_{\mathrm{M}-\mathrm{F}} 1$, resulting in the elimination of a water from methanediol $\mathrm{CH}_{2}(\mathrm{OH})_{2}$ to form the $\mathrm{CH}_{2} \mathrm{O}$. Both the B3LYP and MP2 theoretical levels indicate that this step has a notable barrier above $180 \mathrm{~kJ} / \mathrm{mol}$. The formation of $\mathrm{CH}_{2} \mathrm{O}$ is endothermic by around $30 \mathrm{~kJ} / \mathrm{mol}$. This suggests that the reverse reaction is easier, agreeing with the fact that the methanediol is the dominant form of formaldehyde. Considering water molecules may mediate this reaction in solution, we modeled another mechanism which is shown in Fig. 2(b). $\mathrm{TS}_{\mathrm{M}-\mathrm{F}} 2$ is a six-member ring transition state in which the transfer of a hydrogen atom from one - $\mathrm{OH}$ group to another is mediated by a water molecule. The barrier was calculated to be around $130 \mathrm{~kJ} / \mathrm{mol}$ at all three theoretical levels, significantly lower than that of the fourmember ring mechanism. Therefore, in real situation, the water-mediated mechanism should be dominant. It is believed that the barrier can be further lowered if more explicit water molecules were added, but it is difficult for conventional theoretical methods to deal with a large molecular cluster involving many weak interactions.

Once the urea anion $\left(\mathrm{U}^{-}\right)$is formed, the reaction (3) is possible. We have tried to locate a transition state corresponding to the addition of $\mathrm{U}^{-}$to $\mathrm{CH}_{2} \mathrm{O}$, but such a transition state was not found despite of numerous searches. We speculate that the collision between $\mathrm{U}^{-}$and $\mathrm{CH}_{2} \mathrm{O}$ would directly form a nucleophilic adduct and this is a barrierless process. The adduct $\mathrm{MMU}^{-}$in Scheme-I was optimized and its formation is calculated to be exothermic by $50 \mathrm{~kJ} / \mathrm{mol}$. In reaction (4), the $\mathrm{MMU}^{-}$ abstracts a proton from water, forming the MMU. This reaction 

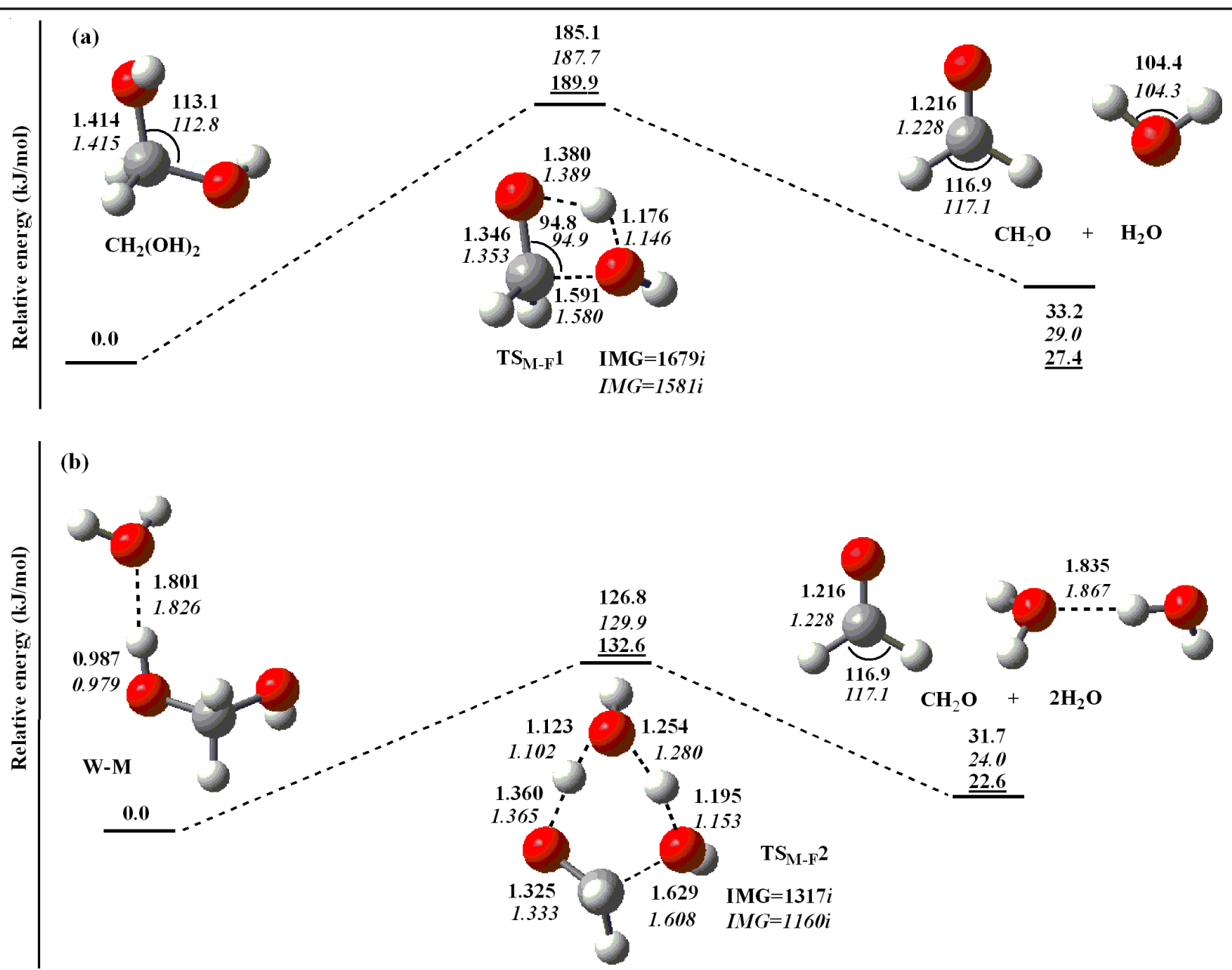

Fig. 2. Optimized geometries (bond lengths in $\AA$ ) for reaction (2) in Scheme-I at B3LYP/6-31+G* and MP2/6-31+G** (italic) levels, respectively, and the calculated relative energies at B3LYP/6-31+G*, MP2/6-31+G** (italic) and MP2/6-311+G** (underlined) levels, respectively
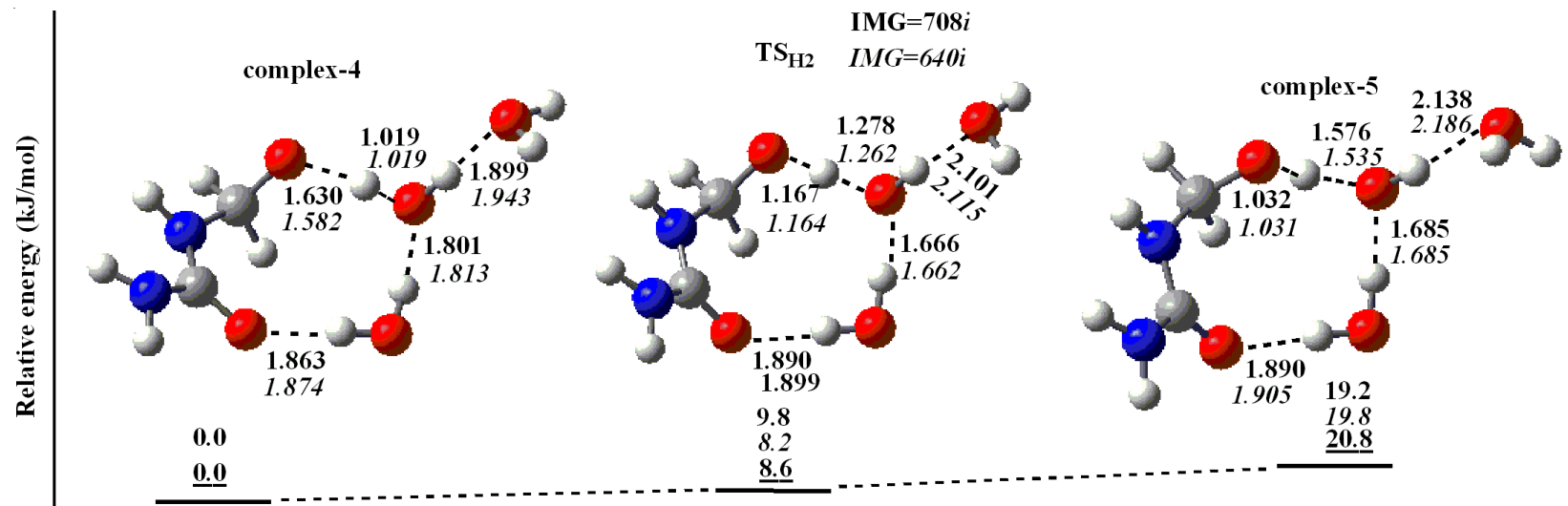

Fig. 3. Optimized geometries (bond lengths in $\AA$ ) for reaction (4) in scheme 1 at B3LYP/6-31+G* and MP2/6-31+G** (italic) levels, respectively and the calculated relative energies at B3LYP/6-31+ $\mathrm{G}^{*}, \mathrm{MP} 2 / 6-31+\mathrm{G}^{* *}$ (italic) and MP2/6-311+G** (the underlined) levels, respectively

was also modeled as shown in Fig. 3. Similarly, three water molecules must be included, otherwise the complexes can not be located. Complex 4 is the reactant complex formed through the interaction between monomethylolurea radical $\left(\mathrm{MMU}^{-}\right)$ and three water molecules. $\mathrm{TS}_{\mathrm{H} 2}$ which has a barrier smaller than $10 \mathrm{~kJ} / \mathrm{mol}$ corresponding to the hydrogen transfer from water to $\mathrm{MMU}^{-}$. The total energy of complex 5 is indeed slightly lower than $\mathrm{TS}_{\mathrm{H} 2}$, but ZPE-correction places it above
$\mathrm{TS}_{\mathrm{H} 2}$ by $10 \mathrm{~kJ} / \mathrm{mol}$. The optimized geometries and flat potential energy profile shown in Fig. 3 suggest that the MMU may exist in the forms of both complex 4 and complex 5 under alkaline condition and an equilibrium should exist between them.

As we mentioned earlier, the neutral urea is not reactive toward methanediol ${ }^{17}$, but the urea anion $\left(\mathrm{U}^{-}\right)$is a stronger nucleophile. Therefore, nucleophilic substitution should be the 
mechanism for reaction (5). By losing a proton, urea can form two anions shown in Fig. 4 as $\mathrm{U}^{-}-1$ and $\mathrm{U}^{-}-2$, respectively. Calculations at both B3LYP and MP2 levels indicate they are almost equally stable. The typical $\mathrm{S}_{\mathrm{N}} 2$ mechanism was identified for the reaction of urea anion $\left(\mathrm{U}^{-}\right)$with $\mathrm{CH}_{2}(\mathrm{OH})_{2}$. The calculated energy barrier is around 180 and $190 \mathrm{~kJ} / \mathrm{mol}$ at B3LYP and MP2 level, respectively.

To understand the role of the two forms of formaldehyde, $\mathrm{CH}_{2} \mathrm{O}$ and $\mathrm{CH}_{2}(\mathrm{OH})_{2}$, we need to return to the reactions in Scheme-I. Reaction (2), (3) and (4) represent pathway A. In this pathway, the reaction (2) is the rate-determining step since the rate constant $\mathrm{k}_{2}$ corresponds to a barrier $130 \mathrm{~kJ} / \mathrm{mol}\left(\mathrm{TS}_{\mathrm{M}-\mathrm{F}} 2\right)$ while reaction (3) and (4) are fast as discussed above. Reaction (5) represent pathway $\mathrm{B}$. In this pathway, $\mathrm{k}_{5}$ corresponds to a higher barrier of $180 \mathrm{~kJ} / \mathrm{mol}\left(\mathrm{TS}_{\mathrm{MMU} 1}\right.$ and $\left.\mathrm{TS}_{\mathrm{MMU} 2}\right)$. Thus, the pathway A is energetically more favourable than pathway B. Considering resin synthesis is generally carried out at temperature range of $60-100{ }^{\circ} \mathrm{C}$, pathway B would also contributes to the formation of MMU.

Formation of di-, tri- and tetra-methylolurea: Under alkaline condition, MMU can form two possible anions and they are denoted as $\mathrm{MMU}^{-}-1$ and $\mathrm{MMU}^{-}-2$. Reactions of them with formaldehyde produce N,N'-dimethylolurea (DMU1) and
N,N-dimethylolurea (DMU2), respectively. The experimental observations suggest that the second methylolation occur mainly on the un-substituted $-\mathrm{NH}_{2}$ group and preferentially form the N,N'-dimethylolurea ${ }^{12,16}$. That is to say, the -NHgroup has lower reactivity than $-\mathrm{NH}_{2}$. What is the main factor to rationalize this result? Electronic or steric hindrance effects? To address this issue, the further methylolations via $\mathrm{S}_{\mathrm{N}} 2$ mechanism were investigated. As it can be seen in Fig. 5, the transition state $\mathrm{TS}_{\mathrm{DMU} 1}$ has an energy barrier of $198.8 \mathrm{~kJ} /$ mol at MP2/6-311+G** level, slightly higher than that of $\mathrm{TS}_{\mathrm{DMU} 2}$ $(192.8 \mathrm{~kJ} / \mathrm{mol})$. Thus, the formation of $\mathrm{N}, \mathrm{N}$ '-dimethylolurea (DMU1) dose not favour over N,N-dimethylolurea (DMU2) in energy. By ruling out the factor of reaction energies, steric hindrance comes out.

Kinetics studies showed that the rate of the reaction of formaldehyde toward MMU is lower, compared to its reaction with free urea ${ }^{16}$. One of the reasons proposed for the decreased reactivity of MMU is the statistical factor, since MMU has only one un-substituted $-\mathrm{NH}_{2}$ group while urea has two. Further, the methylol group might be expected to be electron-withdrawing and hence lower the nucleophilic reactivity of the un-substituted $-\mathrm{NH}_{2}$ group. Based on our calculations, the statistical factor should be dominant because the energy
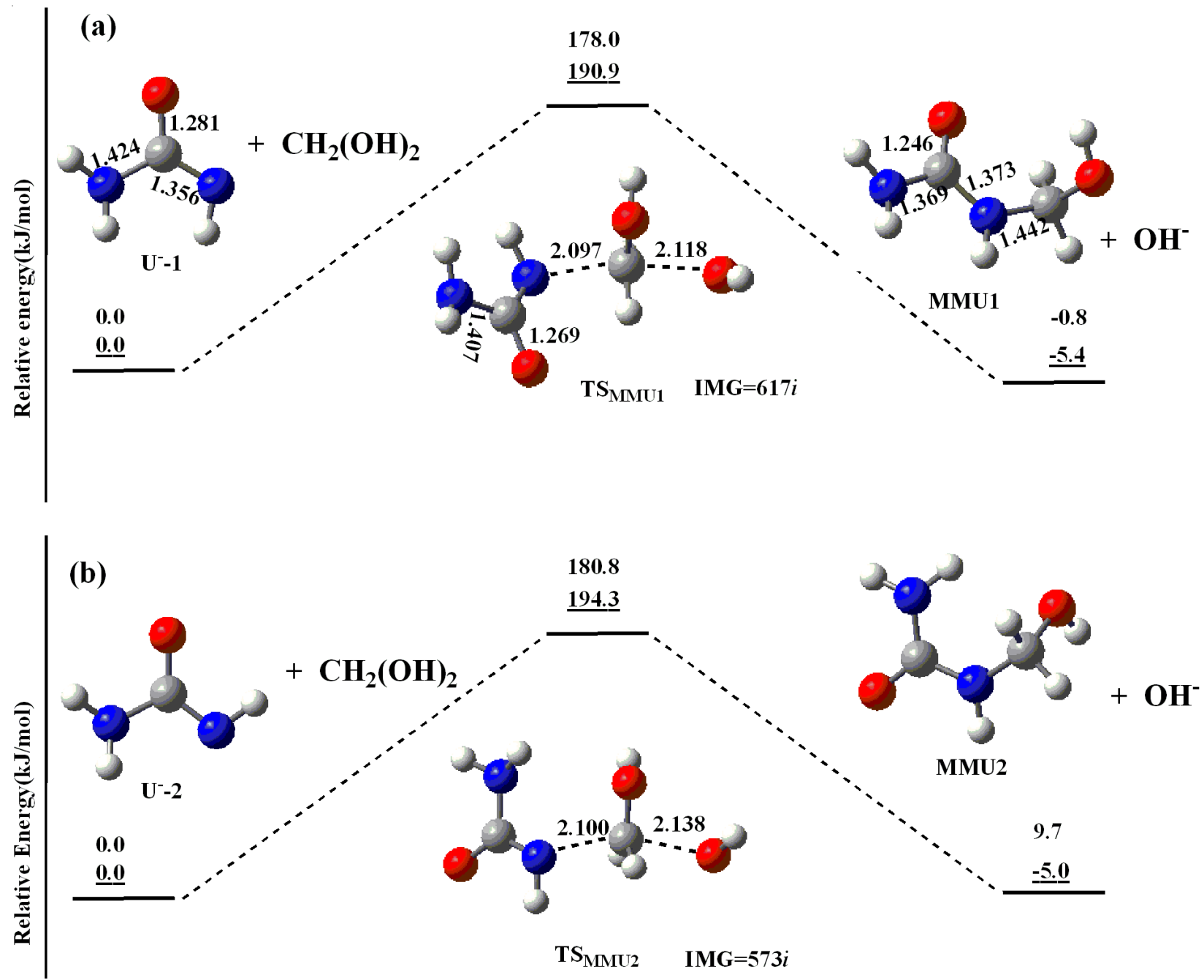

Fig. 4. Optimized geometries (bond lengths in $\AA$ ) for reaction (5) in Scheme-I at B3LYP/6-31+G* and MP2/6-31+G** (italic) level, respectively, and the calculated relative energies at B3LYP/6-31+G* and MP2/6-311+G** (underlined) levels 

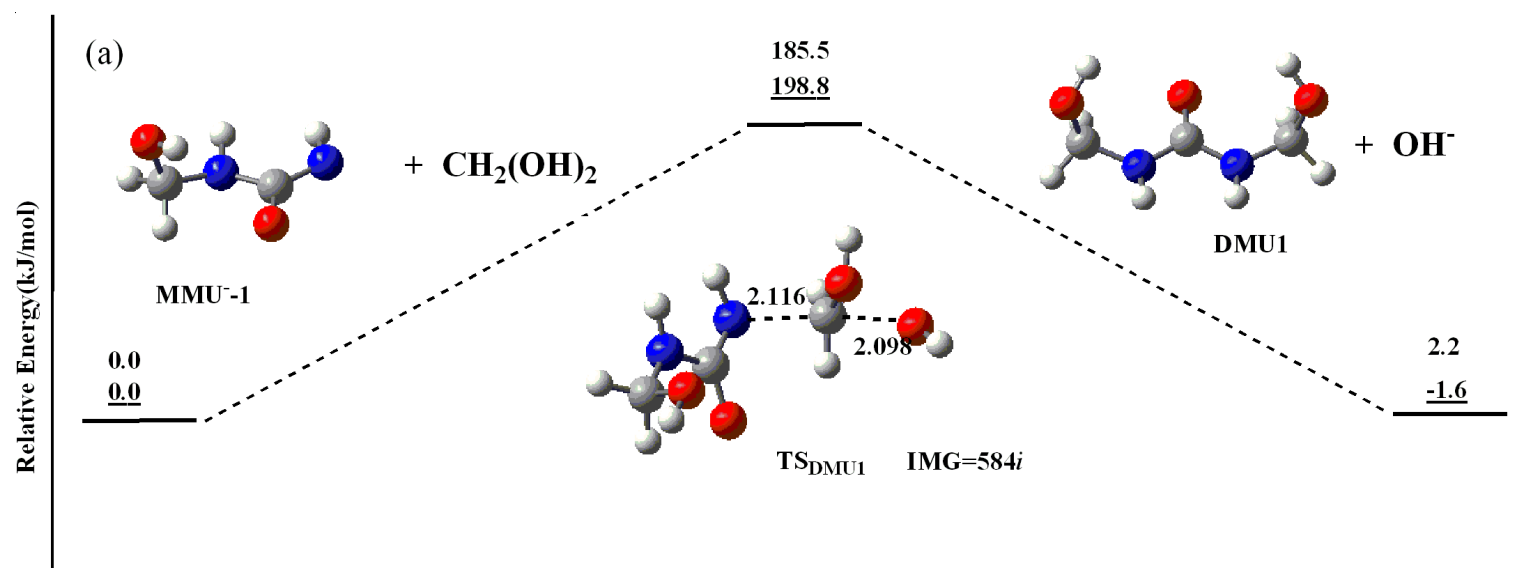

(b)

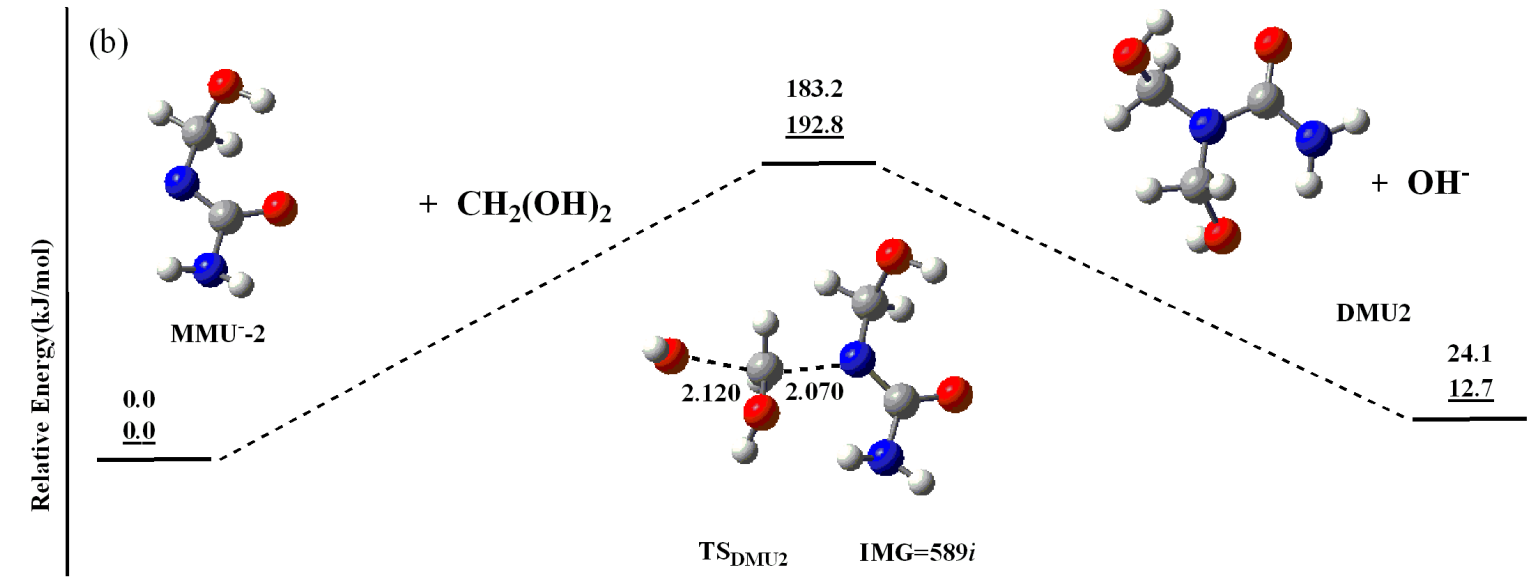

Fig. 5. Optimized geometries (bond lengths in $\AA$ ) for reactions of DMU formation at B3LYP/6-31+G* level and the calculated relative energies at B3LYP/6-31+G* and MP2/6-311+G** (underlined) levels

barriers calculated for free urea and MMU are close, around $190 \mathrm{~kJ} / \mathrm{mol}$ at MP2/6-311+G ${ }^{* *}$ level (Figs. 4 and 5).

Trimethylolurea (TMU) is generally the minor products in experiments. Fig. 6 shows the calculated results for the reaction of dimethylolurea anion $\left(\mathrm{DMU}^{-}\right)$with $\mathrm{CH}_{2}(\mathrm{OH})_{2}$. Compared to MMU and DMU, formation of TMU has a slightly higher energy barrier, but such a small difference can not rationalize the minor formation of TMU. Instead, formations of MMU1 and DMU1 are slightly exothermic or thermochemically neutral, whereas formation of TMU is endothermic by around $30 \mathrm{~kJ} / \mathrm{mol}$. This difference indicates the reverse reaction or hydrolysis of TMU might be stronger. However, this may also not be the main reason. In synthesis of the urea-formaldehyde resin, the F:U molar ratio is generally controlled as $2: 1$ or smaller $^{1,12}$. Thus, formation of MMU and DMU is more competitive and dominant. But by controlling the $\mathrm{F}: \mathrm{U}$ ratio $^{1,12}$, concretely, by adding more formaldehyde, TMU can also be formed and isolated. This is in agreement with our calculated results.

Similar to the formation of MMU, additions between methylolurea anions and the formaldehyde can also produce DMU or TMU and these reactions would have small barriers or be barrierless like reaction (3). But steric hindrance should also affect the direct additions.

Tetramethylolurea (tetra-MU) was never observed in experiments, or at least not produced in detectable quantity ${ }^{12}$. Low reactivity of TMU is believed to be the main reason. The calculated results have elucidated that the substitutions of the methylol groups do not significantly lower the reactivity or nuleophilicity of the -NH- group. We have tried to model the formation of tetramethylolurea, but a completely converged result was not obtained for the optimization of the $S_{N} 2$ transition state at the current theoretical levels. We believe that TMU is still reactive to form tetramethylolurea, but tetramethylolurea would be minor and not stable due to the stronger steric hindrance. The increased structure distortion and steric hindrance from free urea to methylolureas demonstrated in Fig. 7 may help to resolve this issue. In free urea, the indicated dihedral angle is $16.2^{\circ}$ and it is distorted to $-3.7^{\circ}$ in TMU with three hydrogen atoms substituted by methylol groups. In tetramethylolurea, this angle is further changed to $-54.9^{\circ}$, indicating the very strong steric hindrance caused by four methylol groups. To accommodate the substituents, the two N-C bonds have to rotate and subsequently the $\mathrm{p}-\pi$ conjugation between the carbonyl group and nitrogen is destroyed. This change would significantly increase the energy of the structure. In brief, steric hindrance would significantly lower the probability of the reactive collisions between TMU and formaldyhyde to form tetramethylolurea.

\section{Conclusion}

- The catalytic mechanism of base $\left(\mathrm{OH}^{-}\right)$lies in its reaction with urea to produce urea anion or methylolurea anions which are reactive toward $\mathrm{CH}_{2} \mathrm{O}$ and $\mathrm{CH}_{2}(\mathrm{OH})_{2}$.

- $\mathrm{S}_{\mathrm{N}} 2$ is the mechanism for the formation of methylolureas from methanediol. The calculated potential energy barriers for the formations of MMU, DMU and TMU are close, sugges- 


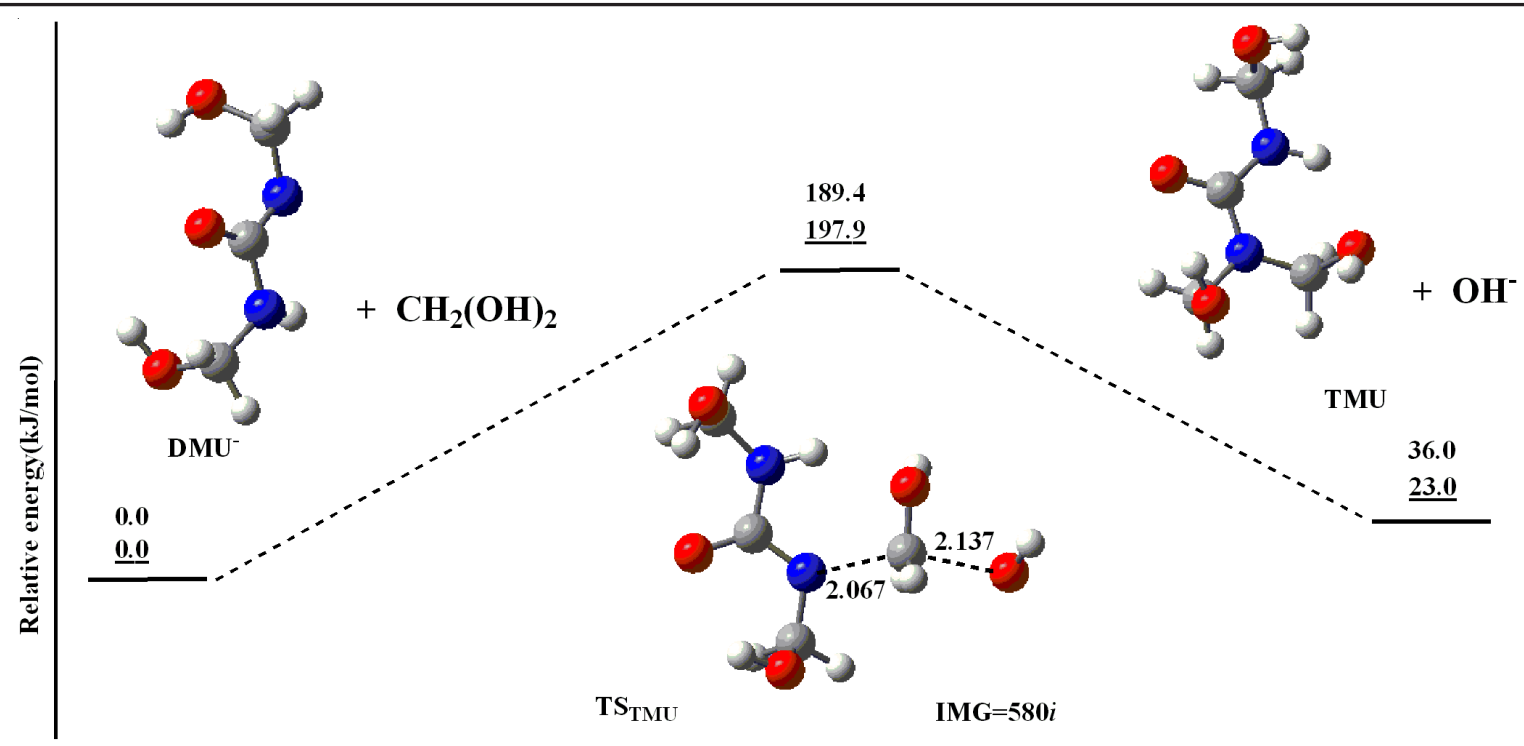

Fig. 6. Optimized geometries (bond lengths in $\AA$ ) for reaction of TMU formation at B3LYP/6-31+G* level and the calculated relative energies at $\mathrm{B} 3 \mathrm{LYP} / 6-31+\mathrm{G}^{*}$ and $\mathrm{MP} 2 / 6-311+\mathrm{G}^{* *}$ (underlined) levels

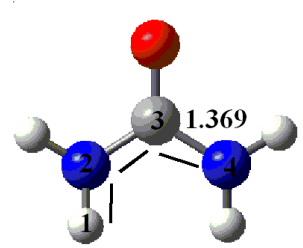

$\mathrm{D}(\mathrm{H} 1-\mathrm{N} 2-\mathrm{C} 3-\mathrm{N} 4)=16.2^{\circ}$

Urea

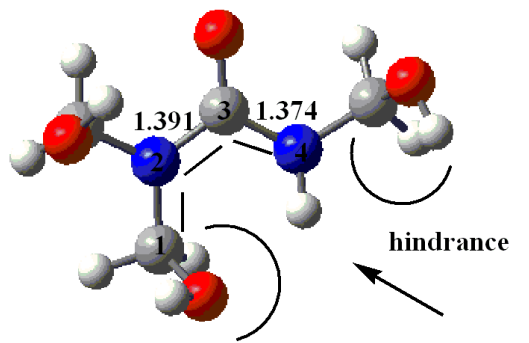

$\mathrm{D}(\mathrm{H} 1-\mathrm{N} 2-\mathrm{C} 3-\mathrm{N} 4)=-3.7^{\circ}$

TMU

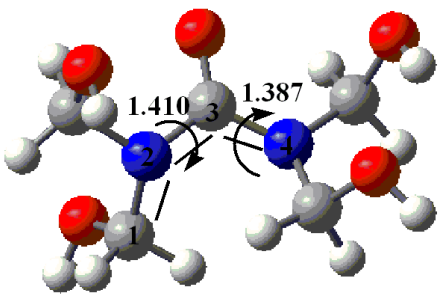

$\mathrm{D}(\mathrm{H} 1-\mathrm{N} 2-\mathrm{C} 3-\mathrm{N} 4)=-54.9^{\circ}$

Tetr-MU

Fig. 7. Increased structure distortion and steric hindrance from free urea to tetramethylolurea

ting that the $-\mathrm{NH}_{2}$ and $-\mathrm{HN}$ - groups have close reactivity toward formaldehyde. Statistical factor may explain the observed lower reactivity of methylolureas than free urea.

- The steric hindrance is the main factor that rationalizes the absence of tetramethylolure in a experiment.

\section{ACKNOWLEDGEMENTS}

This work is supported by the Key Program of the National Science Foundation of China (30930074) and the General Program of the National Science Foundation of China (51273163) and partially supported by the program of the emphatic course construction of Organic Chemistry of Southwest Forestry University.

\section{REFERENCES}

1. M. Dunky, Int. J. Adhes. Adhes, 95, 18 (1998).

2. C. Soulard, C. Kamoun and A. Pizzi, J. Appl. Polym. Sci., 72, 277 (1998).

3. H.R. Mansouri, A. Pizzi and J.M. Leban, Holz. Roh. Werkst, 64, 218 (2006).

4. B. No and Y.M.G. Kim, J. Appl. Polym. Sci., 93, 2559 (2004).

5. C. Cremonini, A. Pizzi and P. Tekely, Holz. Roh. Werkst, 54, 85 (1996).

6. A.S. Angelatos, M.I.N. Burgar and F. Dunlop, J. Appl. Polym. Sci., 91, 3504 (2004).

7. M. Zanetti and A. Pizzi, J. Appl. Polym. Sci., 91, 2690 (2004).
8. M. Zanetti and A. Pizzi, J. Appl. Polym. Sci., 90, 215 (2003).

9. M. Zanetti and A. Pizzi, J. Appl. Polym. Sci., 88, 287 (2003).

10. B.Y. No and M.G. Kim, J. Appl. Polym. Sci., 106, 4148 (2007).

11. G. Du, H. Lei, A. Pizzi and H. Pasch, J. Appl. Polym. Sci., 110, 1182 (2008).

12. E. Minopouloua, E. Dessiprib, G. D. Chryssikosc, V. Gionisc, A. Paipetisc and C. Panayiotoua, Int. J. Adhes. Adhes, 23, 473 (2003).

13. J.I. De Jong and J. De Jonge, Recl. Trav. Chim. Pays-Bas, 71, 643 (1952).

14. J.I. De Jong and J. De Jonge, Recl. Trav. Chim. Pays-Bas, 71, 661 (1952).

15. J.I. De Jong and J. De Jonge, Recl. Trav. Chim. Pays-Bas, 71, 890 (1952).

16. B.R. Nair and D.J. Francis, Polymer, 24, 626 (1983).

17. T.H. Li, C.M. Wang, X.G. Xie and G.B. Du, J. Phys. Org. Chem., 25, 118 (2012).

18. W.F. Xu, S.S. Xiong, Y.Q. Shi, T.H. Li, G.B. Du and X.G. Xie, J. Chin. Struct. Chem., 31, 821 (2012).

19. A.D. Becke, J. Chem. Phys., 98, 1372 (1993).

20. C. Lee, W. Yang and R.G. Parr, Phys. Rev. B, 37, 785 (1988).

21. G.A. Petersson, A. Bennett, T.G. Tensfeldt, M.A. Al-Laham, W.A. Shirley and J. Mantzaris, J. Chem. Phys., 89, 2193 (1988).

22. M. Head-Gordon, J.A. Pople and M.J. Frisch, Chem. Phys. Lett., 503, 153 (1988)

23. S. Miertus, E. Scrocco and J. Tomasi, J. Chem. Phys., 55, 117 (1981).

24. M. Cossi, G. Scalmani, N. Rega and V. Barone, J. Chem. Phys., 117, 43 (2002).

25. A.D. McLean and G.S. Chandler, J. Chem. Phys., 72, 5639 (1980).

26. R. Krishnan, J.S. Binkley, R. Seeger and J.A. Pople, J. Chem. Phys., 72, 650 (1980).

27. M.J. Frisch, et al., Gaussian03, Gaussian, Inc., Pittsburgh PA (2003). 